ISSN 0258-7122 (Print), 2408-8293 (Online)

Bangladesh J. Agril. Res. 44(4): 679-688, December 2019

\title{
SPECIES DIVERSITY AND RICHNESS OF ANT (Hymenoptera, formicidae ) IN BHAWAL NATIONAL PARK OF BANGLADESH
}

\author{
M. M. RAHMAN ${ }^{1}$ AND M. N. JAHAN ${ }^{2}$
}

\begin{abstract}
Ant community serves as an bioindicator on the assumption that the extent of ant diversity reflects broader ecosystem change. Bangladesh with varied agro ecosystem providing broad ecological niche of diversified ant community. The study of ant community is a way to measure the recent transformation of agro ecosystems in Bangladesh to provide information about management and conservation of agricultural landscape. The present study was conducted in Bhawal National Park to delve deeper into the diversity and richness of ants as they work as ecological indicators of an ecosystem. Being a conservation site with natural resources, Bhawal National Park can serve as study site with species diversity due to having sites with similar vegetation and soil type, but different ecological parameters. The objective of the study was to identify local ant fauna in forest agroecosystem to understand the impact on human disturbance to ant communities of the study area. Total 399 individuals were identified from 42 species of 17 genera belonging to 6 subfamilies. Sampling was performed using Time unit sampling (TUS) and pitfall trap in two different areas, viz, area 1 and 2 . The most dominant subfamily of the study area was Myrmicinae. The highest number of species were found from the genus Camponotus. The Shannon-Wiener's Diversity Index showed that area 1 had higher species diversity due to favorable living conditions with less animal intervention and higher density of vegetation playing key role. However, the species dissimilarity in different study areas were relatively low due to similar vegetation and soil type. The study provided an inventory of Bangladesh as well as identification system of ants. This is the first comprehensive list of ants from forest ecosystem of Bangladesh.
\end{abstract}

Keywords: Ant diversity, Bhawal National Park, bioindicator, forest ecosystem

\section{Introduction}

Ant is a eusocial species that plays a crucial role in ecological systems as soil engineers, competitors, predators, scavengers, mutualists, gardeners, and biological agents of insect pests in agriculture (Pal, 2006). In tropical regions, 10$15 \%$ animal biomass in different biotopes constitute of ants making them one of the most abundant insect groups (Agosti et al., 2000). From top of the tall trees to the soil and litters of forests, in almost all territory-based ecosystems, a broad range of 15,000 ants can be found (Andrade et al., 2007). Ants participate in

\footnotetext{
${ }^{1}$ Associate Professor, Department of Entomology, Bangabandhu Sheikh Mujibur Rahman Agricultural University (BSMRAU), ${ }^{2} \mathrm{MS}$ Student, Department of Entomology, BSMRAU, Bangladesh.
} 
various natural cycles that help to reduce climate change hence, considered to be bio-indicators of the quality of forests (Nguyen and Nguyen, 2016). Ant species have been used as soil indicators of mine site rehabilitation (Andersen et al., 2003). They also contribute to modify the physical and chemical properties of soil increasing its drainage and aeration (Dostál et al., 2005) and responsible for altering temperature and other micro climatic variables (Jenkins et al., 2011). High diversity in taxonomy and association with specific settlements make ants a good object in monitoring studies. Thus, ants are usually chosen to compare species diversity at different habitats.

Numerous researches have been conducted recently (Szewczyk and McCain, 2016, Arnan et al., 2017, Belskaya et al. 2017) on ant diversity and functions for ecosystem management. However the association of ant community with agroecosystems needs more detailed study in the tropics.

In Bangladesh, no research was conducted to monitor ant diversity as a tools of bio-indicator in the natural system due to lack of taxonomic information and method for measuring human disturbance. Therefore, the present study was conducted to analyze the diversity of local ant fauna, understand the prevalent ecosystem by correlating it with the presence of ants found in the study area and shed light on the differences in the various ecosystems with the interfering effects in the study area and how it impacts the ant biomass.

\section{Methodology}

\section{Study Area}

The study was conducted in Bhawal National Park $\left(24^{\circ} 01^{\prime} \mathrm{N}, 90^{\circ} 20^{\prime} \mathrm{E}\right)$ during June 2015 to November 2015. The park is situated about $40 \mathrm{~km}$ north of Dhaka, the capital city of Bangladesh, at the heart of Gazipur city. Along with the forest, the park covers 5,000 ha area (Kabir and Ahmed, 2005). Its coverage of this huge area contributes to its biological diversity in both flora and fauna.

\section{Habitat Characterization}

The forest area of the park is a mix of different habitats dominated by Sal forests and rice fields. The topology is classified as low hills that raise $3.0-4.5 \mathrm{~m}$ above the surrounding paddy fields (Kabir and Ahmed 2005). The tree that dominates the forest is Sal (Shorea robusta) covering 90\% of the area. A total of 221 species consisting of 27 grass species, 24 climber species, 3 palm species 105 herb species, 19 shrubs species, and 43 tree species have been identified here. Plants include Careyaa rborea, Dillenia pentagyna, Terminalia belerica, Milius avelutura etc. Among vegetation, Lantala, Melostoma, etc. are commonly found here. Few mammals including Vulpes bengalensis, Canis aureus, Viverricula indica etc. can be seen (Kabir and Ahmed, 2005).

Although it was a reserve forest, the forest have several ecological properties. Some part of this forest is open with foraging fields where people and cattle 
move frequently. This area is bounded by lakes and some aquatic feature as well. Paddy fields are observed in the periphery of this area. The other side is occupied by deep vegetation and relatively undisturbed areas. No such lakes or aquatic environment are observed. For this study, for measuring the diversity and functions of ants, we categorized the two areas as Area 1 and Area 2, respectively based on the type of vegetation and management approaches. The perimeter of both the areas were about $372 \mathrm{~m}$. The two areas are: Open Forest containing foraging fields and lakes that has been mentioned as Area 1 and Deep Forest containing higher vegetation and limited intervention, termed as Area 2 in this paper.

\section{Sampling}

Sampling of ants were done using Time-Unit Sampling (Ogata, 2001) and by setting pitfall trap. In Time-Unit Sampling method, the whole operation was divided into four time-units. Each unit lasted for 15 minutes at stretch. Two persons conducted the operation in 30+ $\alpha$ minutes ( $\alpha$ signifies the gap between two time-units). Ants were searched on the ground, in/under shelters, on lower vegetations and collected using forceps. The key idea in this method is to collect as many ants as possible within a single 15-minute time unit. Each of the time unit samples is independent, so the samples were preserved in their own vials with their own serial code. These vials were prepared beforehand using $70 \%$ ethanol.For pitfall trap method, small containers were placed on the ground with their tops on the surface level. The containers were filled with ethylene glycol. Ants that fell into the trap while roaming around were collected from the containers afterwards for further processing.

\section{Cleaning and Sorting}

Collected specimens were cleaned using brush dipped in water to remove any dirt or other materials. After cleaning, the samples were washed in alcohol and sorted into similar groups. Each group were put in separate vial and labeled accordingly.

\section{Dry Preservation}

The collected specimens were preserved on a dry basis using card points and card mounts. Small triangular pieces of white cardboard, points were made using scissors. Each point was mounted on a macro-pin inserted near the base of the triangle. Using water-soluble glue, the samples were glued to the tip of the point. Multiple ants from same group were placed on one macro-pin.

\section{Identification and Labeling}

Samples were inspected under electronic microscope and identified with their taxonomic keys (Bolton, 1994). The identified ants were properly labeled and 
preserved in the museum of Department of Entomology of Bangabandhu Sheikh Mujibur Rahman Agricultural University for future references.

\section{Statistical Analysis}

For measuring the diversity of ants, few renowned methodology were followed:

\section{1, Shannon-Wiener Diversity Index:}

Shannon-Wiener Diversity Index $\left(\mathrm{H}^{\prime}\right)$ (Krebs, 1999) was calculated to determine the species diversity in each study area. It measures the amount of order (or disorder) contained in a system (Margalef, 1958). The value is given by:

$\mathrm{H}^{\prime}=\sum_{i=1}^{s} p_{i} \operatorname{In}\left(p_{i}\right)$

where,

$s=$ Number of Species

$\mathrm{p}_{\mathrm{i}}=$ Proportion of the Total Sample Belonging to the $i$-th Species

\section{The Evenness Index:}

The Evenness Index $\left(\mathrm{J}^{\prime}\right)$ (Krebs 1999) was calculated to determine the equal abundance of ants in each study area. The value is given by:

$\mathrm{J}^{\prime}=\frac{H^{\prime}}{H_{\max }^{\prime}}$

where,

$\mathrm{H}^{\prime}=$ Observed Index of Species Diversity

$\mathrm{H}^{\prime}{ }_{\max }=$ Maximum Possible Index of Diversity

\section{Effective Number of Species:}

Effective Number of Species (ENS) (Jost, 2006) was calculated using the Shannon-Wiener Diversity Index $\left(\mathrm{H}^{\prime}\right)$ to find the true diversity of the areas in question. This helped us to find an actual measure to compare and contrast the two study areas. The value is given by:

$\mathrm{ENS}=\mathrm{e}^{\mathrm{H}^{\prime}}$

where,

$\mathrm{H}^{\prime}=$ Observed Index of Species Diversity 


\section{Bray-Curtis Dissimilarity:}

Bray-Curtis Dissimilarity $(B C)$ (Bray and Curtis 1957) was calculated to quantify the compositional dissimilarity between two areas. The result is often multiplied by 100 and treated as percentage. The value is given by:

$\mathrm{BC}=1-\frac{2|X \cap Y|}{|X|+|Y|}$

where,

$|\mathrm{X} \cap \mathrm{Y}|=$ Number of species common in both areas

$|\mathrm{X}|=$ Total number of species in area 1

$|\mathrm{Y}|=$ Total number of species in area 2

\section{Statistica Package:}

Statistica Package $\mathrm{R}$ was used for generating the graph on species diversity in two areas.

\section{Results and Discussion}

A total of 399 individuals of 42 species in 17 genera distributed among 6 subfamilies were collected from two areas using time-unit sampling and pitfall traps. The detailed checklist can be found in Table 1. Among the subfamilies, Myrmicinae thrives having 215 samples from 8 genera consisting of 20 different species followed by Ponerinae and Dorylinae, respectively. The highest number of ants were identified from Pheidole followed by Camponotus and Dolichoderus. Both the areas were dominated by 6 different species from the the genus Camponotus.

The most dominant species in both the areas of Bhawal National Park is $D$. affinisoccupying $7.27 \%$ of the identified samples, followed by $P$. binghamiiand M. brunnea (Table 2). Area 2 was found more diverse with species richness than that of Area 1. Thirty Four species of ants in 16 genera were found in Area 2, while, 27 species of ants in 14 genera were identified in Area 1. This can be attributed to diverged vegetation pattern incorporated with the lack of human intervention and no foraging activity in Area 2. Bhawal National Park is dominated by deciduous Sal tree. The leaves of these trees fall off every year. Fallen leaves are decomposed by microorganisms resulting in higher nutrient content. This is why ants seek refuge in places with high vegetation. Moreover, limited human access and lack of foraging activities facilitate free movement of ants. This has made the place an ant sanctuary. On the contrary, Area 1 is facilitated with lakes and crop fields that allow intervention of cattle and human along with some aquatic insectivores. These make the area less suitable for ants. 
Table 1. Species diversity of different ant fauna in Bhawal National Park

\begin{tabular}{llcc}
\hline \multicolumn{1}{c}{ Subfamily } & \multicolumn{1}{c}{ Genera } & Number of Species & Total Individuals \\
\hline Dolichoderinae & Dolichoderus & 2 & 41 \\
& Camponotus & 6 & 55 \\
Dorylinae & Cerapachys & 1 & 5 \\
Formicinae & Oecophylla & 1 & 21 \\
& Crematogaster & 3 & 35 \\
& Meranoplus & 2 & 29 \\
& Myrmica & 2 & 11 \\
Myrmicinae & Myrmicaria & 2 & 32 \\
& Pheidole & 5 & 65 \\
& Solenopsis & 1 & 14 \\
& Tetramorium & 2 & 13 \\
& Trichomyrmex & 3 & 16 \\
& Anochetus & 2 & 8 \\
Ponerinae & Diacamma & 3 & 22 \\
& Leptogenys & 3 & 9 \\
Pseudomyrmecinae & Tetraponera & 1 & 4 \\
\hline Total & & 3 & 399 \\
\hline
\end{tabular}

Table 2. Relative abundance of listed ant species in two areas

\begin{tabular}{cll|c|c|c|c}
\hline \multicolumn{1}{c}{ Genus } & \multicolumn{1}{c}{ Species } & Area 1 & Area 2 & Total & Occurrence (\%) \\
\hline \multirow{2}{*}{ Dolichoderus } & D. affinis & 9 & 20 & 29 & $7.27 \%$ \\
& D. taprobanae & 0 & 12 & 12 & $3.01 \%$ \\
\hline \multirow{5}{*}{ Camponotus } & C. angusticollis & 4 & 2 & 6 & $1.50 \%$ \\
& C. festinus & 7 & 11 & 18 & $4.51 \%$ \\
& C. fulvopilosus & 4 & 3 & 7 & $1.75 \%$ \\
& C. oblongus & 3 & 5 & 8 & $2.01 \%$ \\
& C. rufoglaucus & 0 & 6 & 6 & $1.50 \%$ \\
\hline Cerapachys & C. siemsseni & 0 & 10 & 10 & $2.51 \%$ \\
\hline Oecophylla & C. sulcinodis & 0 & 5 & 5 & $1.25 \%$ \\
\hline
\end{tabular}




\begin{tabular}{|c|c|c|c|c|c|}
\hline Genus & Species & Area 1 & Area 2 & Total & Occurrence $(\%)$ \\
\hline \multirow{3}{*}{ Crematogaster } & C. abdominalis & 9 & 5 & 14 & $3.51 \%$ \\
\hline & C. binghamii & 4 & 8 & 12 & $3.01 \%$ \\
\hline & C. rufa & 3 & 6 & 9 & $2.26 \%$ \\
\hline \multirow{2}{*}{ Meranoplus } & M. laeviventris & 7 & 0 & 7 & $1.75 \%$ \\
\hline & M. rothneyi & 0 & 22 & 22 & $5.51 \%$ \\
\hline \multirow{2}{*}{ Myrmica } & M. indica & 4 & 4 & 8 & $2.01 \%$ \\
\hline & M. rugosa & 0 & 3 & 3 & $0.75 \%$ \\
\hline \multirow{2}{*}{ Myrmicaria } & M. brunnea & 0 & 22 & 22 & $5.51 \%$ \\
\hline & M. fodiens & 0 & 10 & 10 & $2.51 \%$ \\
\hline \multirow{5}{*}{ Pheidole } & P. binghamii & 0 & 25 & 25 & $6.27 \%$ \\
\hline & P.feae & 13 & 3 & 16 & $4.01 \%$ \\
\hline & $P$. indica & 8 & 0 & 8 & $2.01 \%$ \\
\hline & P. roberti & 0 & 7 & 7 & $1.75 \%$ \\
\hline & P. noda & 4 & 5 & 9 & $2.26 \%$ \\
\hline Solenopsis & S. geminata & 0 & 14 & 14 & $3.51 \%$ \\
\hline \multirow{2}{*}{ Tetramorium } & T. belgaense & 3 & 0 & 3 & $0.75 \%$ \\
\hline & T. indicum & 4 & 6 & 10 & $2.51 \%$ \\
\hline \multirow{3}{*}{ Trichomyrmex } & T. criniceps & 3 & 4 & 7 & $1.75 \%$ \\
\hline & T. destructor & 0 & 7 & 7 & $1.75 \%$ \\
\hline & T. mayri & 2 & 0 & 2 & $0.50 \%$ \\
\hline \multirow{2}{*}{ Anochetus } & A. cryptus & 0 & 3 & 3 & $0.75 \%$ \\
\hline & A. rufus & 4 & 1 & 5 & $1.25 \%$ \\
\hline \multirow{3}{*}{ Diacamma } & D. assamense & 4 & 0 & 4 & $1.00 \%$ \\
\hline & D. ceylonense & 0 & 6 & 6 & $1.50 \%$ \\
\hline & D. indicum & 7 & 5 & 12 & $3.01 \%$ \\
\hline \multirow{3}{*}{ Leptogenys } & L. assamensis & 0 & 4 & 4 & $1.00 \%$ \\
\hline & L. falcigera & 3 & 0 & 3 & $0.75 \%$ \\
\hline & L. roberti & 1 & 1 & 2 & $0.50 \%$ \\
\hline \multirow[t]{2}{*}{ Odontoponera } & O. denticulata & 4 & 0 & 4 & $1.00 \%$ \\
\hline & T. binghami & 3 & 7 & 10 & $2.51 \%$ \\
\hline \multirow[t]{2}{*}{ Tetraponera } & T. nigra & 3 & 2 & 5 & $1.25 \%$ \\
\hline & T. rufonigra & 4 & 0 & 4 & $1.00 \%$ \\
\hline
\end{tabular}

Between the two areas, Area 2 scores higher Shannon-Wiener Diversity Index compared to Area 1. This result is shown in Table 3. These findings support previous phenomenon of higher abundance of species in Area 2. The evenness index of both areas are close to 1, denoting that in both areas the number of 
species are close to each other. Evenness index works better when the number of sample is higher. However, it fails to capture the intricate difference between evenness of species for smaller sample sizes as shown in this case. For this reason, the effective number of species were calculated. It shows us the degree of unevenness or dominance of species in the area. It emphasizes the result of Shannon-Wiener Diversity Index as it weighs each species exactly according to its frequency. Even though there were 34 species found Area 2, the effective number of species is far lesser denoting the huge difference between the contribution of each species in the biomass of the area. The Bray-Curtis Dissimilarity between Area 1 and Area 2 is 0.377 . That means the two areas have $37.7 \%$ dissimilarity between them. The reasoning behind this can be the similarity in vegetation of the two areas.

Table 3: Shannon-Wiener Diversity, Evenness Index and Effective Number of Species of the two areas

\begin{tabular}{|c|c|c|c|c|c|}
\hline Area & Number of Species & Number of Samples & $\mathrm{J}^{\prime}$ & $\mathrm{H}^{\prime}$ & ENS \\
\hline 1 & 27 & 135 & 0.96 & 3.15 & 23 \\
\hline 2 & 34 & 264 & 0.92 & 3.26 & 26 \\
\hline
\end{tabular}

8 species from 7 genera were exclusive to area 1 whereas 15 species from 12 genera were exclusive to area 2, however, 11 species were common in both areas (Fig. 1).

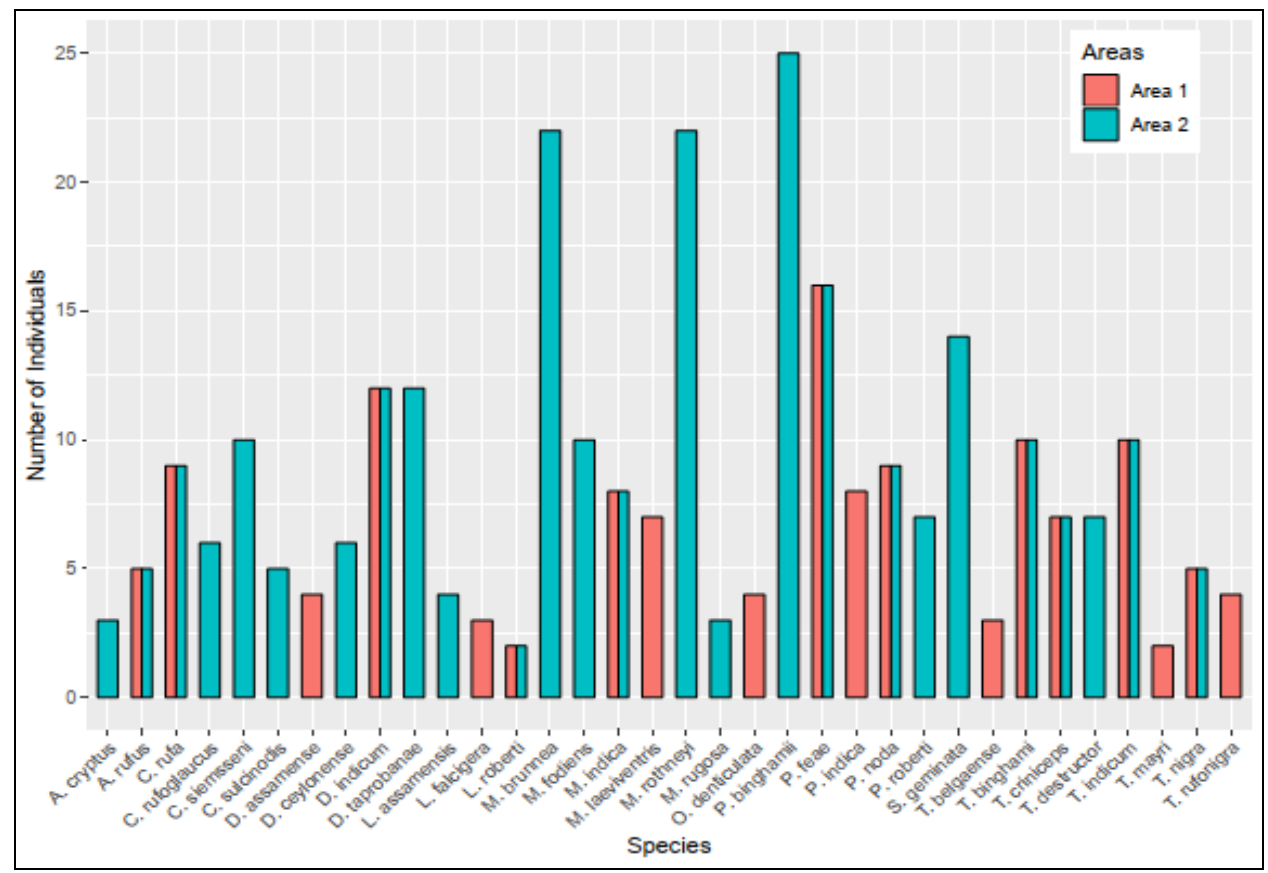

Fig. 1. Relative distribution of ant species in the two areas. 


\section{Conclusion}

The diversity and richness of ants in Bhawal National Park was highlighted in this study. A total of 42 species from 17 genera distributed among 6 subfamilies were identified. The difference in species composition found can be attributed to the difference in the habitats of the study area. Higher density in vegetation and lack of animal intervention resulted higher diversity index. However, similarity in regions were found due to homogenous vegetation pattern. As ants are using to measure and monitor biodiversity in different agroecosystem, therefore, the findings of this study will be useful to evaluate recent biodiversity and the effects of agricultural intensification. This study of the ant community of Bhawal national park will be a way to measure the transformation of agroecosystemsand can provide information about management and conservation of agricultural landscape by studying the impacts of disturbance on ant communities in agroecosystem of Bangladesh.

\section{Acknowledgement}

The authors are thankful to Dr. Nguyen Van Thinh, Research fellow, Institute of Tropical Agriculture, Kyushu University, Japan for his generous support of processing the data of identified ant samples for this study.

\section{Conflict of interest}

The authors declare that there is no conflict of interest regarding the publication of this paper.

\section{References}

Agosti. D, J. D. Majer, L. E. Alonso and T. R. Schultz. 2000. Ants: Standard Methods for Measuring and Monitoring Biodiversity. Smithsonian Inst. Press, Washington.

Andersen, A. N., B. D. Hoffmann and J. Somes. 2003. Ants as indicators of minesite restoration: community recovery at one of eight rehabilitation sites in central Queensland. Ecological Management \& Restoration 4. pp. S12-19.

Andrade, T, G. D. Marques and K. Del-Claro. 2007. Diversity of ground dwelling ants in cerrado: an analysis of temporal variations and distinctive physiognomies of vegetation (Hymenoptera: Formicidae). Sociobiology. 50(1): 121-34.

Arnan, X, X. Cerdá and J. Retana. 2017. Relationships among taxonomic, functional, and phylogenetic ant diversity across the biogeographic regions of Europe. Ecography. 40(3): 448-57.

Bolton, B. 1994. Identification guide to the ant genera of the world. Harvard University Press.

Bray, J. R. and J. T. Curtis. 1957. An ordination of upland forest communities of southern Wisconsin. Ecological Monographs. 27: 325-349.

Dostál, P., M. Březnová, V. Kozlíčková, T. Herben and P. Kovár. 2005. Ant induced soil modification and its effect on plant below-ground biomass. Pedobiologia 49: 2:127-137. 
Jenkins, C.N., N. J. Sanders, A. N. Andersen, X. Arnan, C. A. Brühl, X. Cerda, A. M. Ellison, B. L. Fisher, M. C. Fitzpatrick, N. J. Gotelli and A. D. Gove. 2011. Global diversity in light of climate change: the case of ants. Diversity and Distributions 17: 4:652-662.

Jost, L. 2006. Entropy and diversity. Oikos. 113(2): 363-75.

Kabir, D. S. and A. Z. Ahmed. 2005. Wildlife biodiversity in Bhawal National Park: Management techniques and drawbacks of wildlife management and nature conservation. Our Nature. 3(1): 83-90. doi: https://doi.org/10.3126/on.v3i1.340

Krebs, C. J. 1999. Ecological Methodology. Addison Wesley Longman, Menlo Park, CA.

Margalef, R. 1958. Information Theory in biology. General Systems Yearbook. 3: 36-71.

Nguyen, D. D. and L. T. Nguyen. 2016. Diversity and abundance of ants (Hymenoptera: Formicidae) in Phu Luong, Thai Nguyen province, Vietnam.

Ogata, K. 2001. Time Unit Sampling: a Protocol. ANeT Newsletter. No. 3: 18-19.

Pal, K. K. and B. M. Gardener. 2006. Biological control of plant pathogens. The Plant Health Instructor.

Szewczyk, T. and C. M. McCain. 2016. A systematic review of global drivers of ant elevational diversity. PLoSOne. 11(5): e0155404. 